\title{
Effect of Nonprotective Vaccination on Antibody Response to Subsequent Human Immunodeficiency Virus Infection
}

\author{
Seth H. Pincus, Katherine G. Messer, and Shiu-Lok Hu * \\ Laboratory of Microbial Structure and Function, Rocky Mountain Laboratories, National Institute of \\ Allergy and Infectious Diseases, National Institutes of Health, Hamilton, Montana 59840;
}

and *Bristol-Myers Squibb Pharmaceutical Research Institute, Seattle, Washington 98121

\begin{abstract}
We have investigated the systemic anti-HIV antibody response in chimpanzees who were immunized with live vaccinia containing either the HIV envelope glycoprotein $\left(\mathrm{gp}_{160_{\mathrm{IIB}}}\right)$ or a control antigen (herpes simplex virus glycoprotein D) and then challenged with either a high dose $\left(300,000\right.$ TCID $\left._{50}\right)$ or low dose $\left(100 \mathrm{TCID}_{50}\right)$ of $\mathrm{HIV}_{\text {IIIB }}$. HIV was subsequently isolated from all animals, indicating failure of the vaccination to protect against HIV infection. Serum antibody responses were evaluated before immunization, at the time of challenge with HIV, and at multiple time points in the 9 mo after challenge. Immunization resulted in a more rapid rise of antibody to gp160 in both high and low dose animals. Antibodies to the V3 loop induced upon infection were unaffected by immunization. In low dose animals, neutralizing antibody rose more rapidly and to higher levels in the immunized animals as compared with the control. There was no difference in neutralizing antibodies between immunized and control chimpanzees in the high dose group. Epitope mapping of the anti-gp160 response indicated that immunization with gp160 vaccinia induced a postinfection antibody response to a region of gp41 (amino acids 718-743) that was not immunogenic in control-vaccinated animals. These data indicate that failed vaccination with the HIV envelope can alter both the timing and epitope specificity of the subsequent antiHIV antibody response. These studies also define the evolution and fine specificity of the antibody response during the critical period immediately postinfection. (J. Clin. Invest. 1994. 93:140-146.) Key words: HIV • AIDS • vaccine • vaccinia
\end{abstract}

\section{Introduction}

The development of an effective vaccine to prevent infection with HIV is of major importance in preventing the worldwide spread of AIDS. The effort to develop a vaccine has involved studies in nonhuman primates (1-7) as well as phase I clinical trials in humans (8-13). Although protection has been obtained in some simian models, extension of these results to humans might be problematic, since protection was obtained against challenge in very controlled circumstances, usually at the peak of the immune response resulting from immunization. Vaccine efficacy trials are currently being planned, driven

Address correspondence to Dr. Seth H. Pincus, Laboratory of Microbial Structure and Function, Rocky Mountain Laboratories, Hamilton, MT 59840. 1993.

Received for publication 9 June 1993 and in revised form 11 August

The Journal of Clinical Investigation, Inc.

Volume 93, January 1994, 140-146 by the perceived need for vaccines to halt the ongoing spread of AIDS (14). In view of the uncertainties in AIDS vaccine development, we must consider the possibility that early efficacy trials may fail.

Initial human trials have used subunit vaccines based upon the HIV envelope protein (s) gp160 and gp120, and have found them to be weakly immunogenic $(8,10-12)$. However, one protocol, involving vaccination with a vaccinia virus expressing gp160 followed by booster immunization with recombinant gp160, induced high titers of anti-gp160 $(9,15)$. Moreover, a similar protocol using simian immunodeficiency virus gp160 protected macaques against challenge with infectious simian immunodeficiency virus (5). Because this protocol uses substantially less recombinant antigen and induces a greater immune response, gp 160 vaccinia priming may be a candidate for future phase II and III clinical trials.

Although reports of HIV vaccine trials in chimpanzees have evaluated their antibody response after immunization, as well as protection against infectious challenge, none has studied the postinfection response in detail. Defining the immune response after unsuccessful vaccination should provide information regarding both the evolution of an immune response after infection with a defined virus and the effect of immunization on this response. We have recently compared the fine specificity of the anti-HIV envelope antibody response in vaccinees and in lab workers infected with the same strain of HIV (IIIB/ LAV), and found significant differences in the responses induced by immunization vs. natural infection (15). In this work, we have used similar techniques to study the systemic antibody response in chimpanzees that were immunized with vaccinia expressing gp $160_{\mathrm{III}}$, but were not protected against subsequent challenge with the homologous strain of HIV. The data indicate that failed vaccination with the HIV envelope can alter both the kinetics and epitope specificity of subsequent antibody responses to HIV infection. Alterations induced by failed vaccination of chimpanzees resembled those of humans immunized with gp160 vaccinia. These data implicate gp160 vaccinia as inducing antibody to a specific epitope.

\section{Methods}

$H I V$ strains. The vaccine used in this manuscript expressed the envelope protein derived from the LAV (LAI) strain of HIV (16). The envelope protein of the molecularly cloned HIV isolate NL4-3 was also derived from LAV (17). The chimpanzees were infected with the HTLV-IIIB strain of HIV that had been passaged twice through chimpanzees (3). Whether LAV and IIIB are distinct isolates remains a matter of contention, but the sequences of the two isolates are highly related. There are small differences in the envelope sequences of the two isolates, as there are between molecular clones of the IIIB isolate. For the sake of consistency, we will refer to these strains as IIIB throughout the manuscript. 
Immunization and infectious challenge. Chimpanzees were housed at the Southwest Foundation for Biomedical Research (San Antonio, TX). The study was conducted under a National Institutes of Health approved animal protocol. Vaccine consisted of recombinant vaccinia virus (New York City Board of Health strain) expressing either HIV gp160 ${ }_{\text {IIIB }}$ or herpes simplex virus type I glycoprotein D (gD) ${ }^{1}$. Chimpanzees were vaccinated with $1-2 \times 10^{8}$ plaque-forming units of vaccinia virus by scarification with a bifurcated needle on two occasions 8 wk apart. 8 wk after the second vaccination, the chimpanzees were challenged intravenously with either 300,000 or 100 tissue culture infective dose $50 \%\left(\right.$ TCID $\left._{50}\right)$ HIV-1 $1_{\text {IIIB }}$. Animals were bled serially for 1 yr after the infectious challenge. HIV was isolated from peripheral blood mononuclear cells of all chimpanzees. HIV was first isolated 2-3 wk after infectious challenge, and was consistently present for the first 3 mo postinfection. There was no difference in kinetics or magnitude of HIV isolation between gp 160 and gD-immunized chimpanzees. Table I identifies each animal, its vaccination, and challenge dose.

Immunoassays. All assays used in this study are described in detail elsewhere (15). ELISAs were performed on recombinant protein adhered to microtiter wells at $1 \mu \mathrm{g} / \mathrm{ml}$, and soluble peptides at $5 \mu \mathrm{g} / \mathrm{ml}$. Serum samples were tested at a 1:1,000 dilution. The following recombinant antigen was used: gp $160_{\text {IIIB }}$ denatured in $8 \mathrm{M}$ urea (Repligen, Cambridge, MA). Synthetic peptides were synthesized using a peptide synthesizer (431A; Applied Biosystems, Inc., Foster City, CA). The following synthetic peptides were used: V1 (amino acids [AA] 131156 ; numbering according to reference 18 , sequence of $\mathrm{HXB}-2 \mathrm{~B}$ ), CTDLKNDTNTNSSSGRMIMEKGEIKNC; V3 (AA 297-330), TRPNNNTRKSIRIQRGPGRAFVTIGKIGNMRQAH; and midgp41 (AA 718-743), QTHLPTPRGPDRPEGIEEEGGERDRD. Chimpanzee antibodies were detected with alkaline phosphatase-conjugated anti-human immunoglobulins (anti-IgG, IgA, IgM; Zymed Laboratories, South San Francisco, CA) and $p$-nitrophenyl phosphate substrate (Sigma Chemical Co., St. Louis, MO). Data are reported as optical density at $405 \mathrm{~nm}$ and represent means of triplicate values.

Epitope scanning was performed by the method of Geysen et al. (19). A set of 283 overlapping 12-mer peptides was constructed on solid supports (Chiron Mimotopes, Emeryville, CA). Peptides began every third AA (starting at the amino terminus), and thus had a nine$A A$ overlap. Sequences used to construct the peptides conform to those of the BH10 isolate of HTLV-IIIB. Five control pins with irrelevant peptides were included. Before use the peptides were blocked with $3 \%$ BSA (Sigma Chemical Co.), $0.1 \%$ Tween-20 in PBS. The supports were incubated with the test serum diluted 1:5,000 in PBS, 1\% BSA, followed by successive washings and incubation with alkaline phosphatase-conjugated goat anti-human Ig antibody and then substrate. Data are reported with the background absorbance of the control pins subtracted. After each use of the peptide support matrix, antibodies were rigorously desorbed and the pins tested for residual antibody (15).

Virus neutralization was performed using a focal infectivity assay (FIA) $(15,20-22)$. The molecularly cloned HIV strain NL4-3 was used in the neutralization assays. A pretitered dilution of cell-free virus was mixed with the serum to be tested and incubated for $1 \mathrm{~h}$ at $37^{\circ} \mathrm{C}$. The mixture was then transferred to a monolayer of CD4 ${ }^{+} \mathrm{HeLa}$ cells (cell line 1022) for $3 \mathrm{~h}$. The monolayer was washed free of virus and antibody, and fresh media were added and incubated for $3 \mathrm{~d}$. The cells were fixed and HIV-infected cells identified by immunoperoxidase staining associated with the characteristic morphology of a syncytium.

\section{Results}

Antibody to recombinant Env protein. Fig. 1 shows the binding of serum antibodies to recombinant envelope protein gp 160. A small increase in antibody was seen $2 \mathrm{wk}$ after the booster vacci-

1. Abbreviations used in this paper: AA, amino acids, FIA, focal infectivity assay; $\mathrm{gD}$, glycoprotein $\mathrm{D} ; \mathrm{TCID}_{50}$, tissue culture infective dose $50 \%$.
Table I. Chimpanzees Used in This Study

\begin{tabular}{clr}
\hline Chimpanzee & Vaccinating Ag* & Infectious dose \\
\hline & & $T C I D_{s 0}$ \\
124 & HIV gp160 & 300,000 \\
149 & HIV gp160 & 300,000 \\
134 & HSV gD & 300,000 \\
72 & HIV gp160 & 100 \\
216 & HIV gp160 & 100 \\
64 & HSV gD & 100 \\
\end{tabular}

* Chimpanzees received two doses of the New York Board of Health strain of vaccinia expressing either HIV gp160 or herpes simplex virus $\mathrm{gD}$.

nation in several of the experimental animals. However, no appreciable antibody was made until postinfection. The postinfection development of anti-gp 160 antibodies was delayed 2-4

HIGH DOSE INFECTION

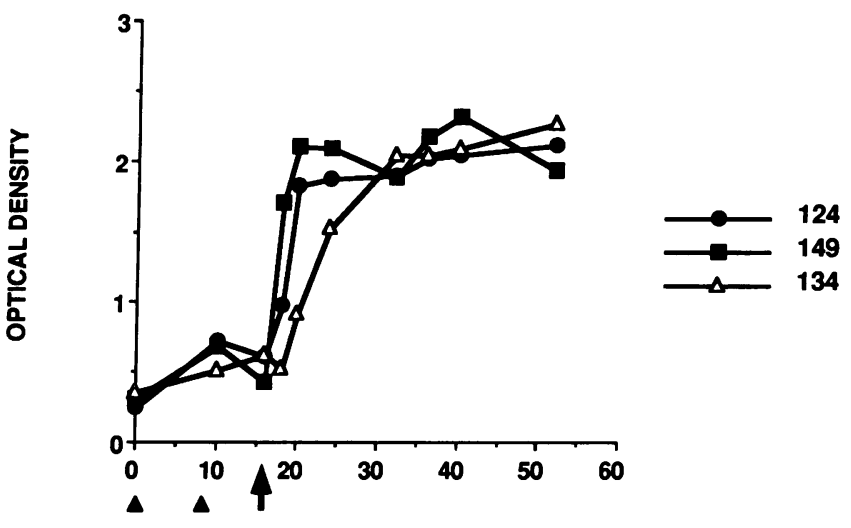

LOW DOSE INFECTION

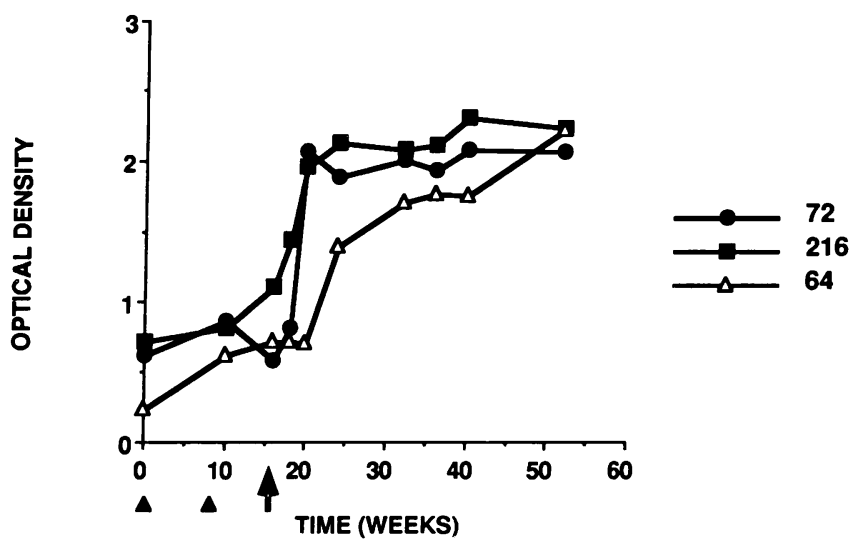

Figure 1. Production of anti-gp160 antibody. Anti-gp 160 antibody was measured by ELISA. Recombinant gp 160 was adsorbed to microtiter wells. Chimpanzee serum was tested at a 1:1,000 dilution. Antibody binding was detected with alkaline phosphatase-conjugated anti-human Igs. Optical density is shown on the vertical axis. The horizontal axis shows time in weeks after the initial vaccination. Dates of vaccination are indicated with the triangles below the horizontal axis, the challenge with an arrow. Control chimpanzees (immunized with herpes symplex virus $\mathrm{gD}$ ) are indicated with open triangles. 
wk in the control animals compared with those receiving gp160 vaccine. Antibody levels in all animals remained high throughout the year after infection. Although this ELISA was performed with denatured gp160, similar results were seen when sera were tested on native (i.e., CD4-binding) Vero cell-expressed gp 160.

Anti-V3 antibodies. Antibody to the V3 loop of gp120, a principal neutralizing and tropism-determining domain, was assayed on peptides in two different ways. First, the amount of antibody was measured on a peptide (AA 297-330) representing the entire V3 loop, except its terminal cysteines (Fig. 2). Second, the fine specificity was determined on a set of overlapping 12-mer peptides (Fig. 3). As indicated in Fig. 2, no antiV3 antibody was induced by vaccination before infection. After infection, antibody levels did not appear to rise more rapidly, nor did they reach higher levels in gp160-vaccinated animals compared with controls. In most chimpanzees the level of anti-V3 antibody reached a peak, and then began to decline, as opposed to antibody levels to the entire gp160, which maintained a plateau level for the entire time (Fig. 1). The fine specificity of the anti-V3 response was affected neither by prior vaccination nor by infective dose (Fig. 3). However, there was a consistent evolution of the response with time after

\section{HIGH DOSE INFECTION}

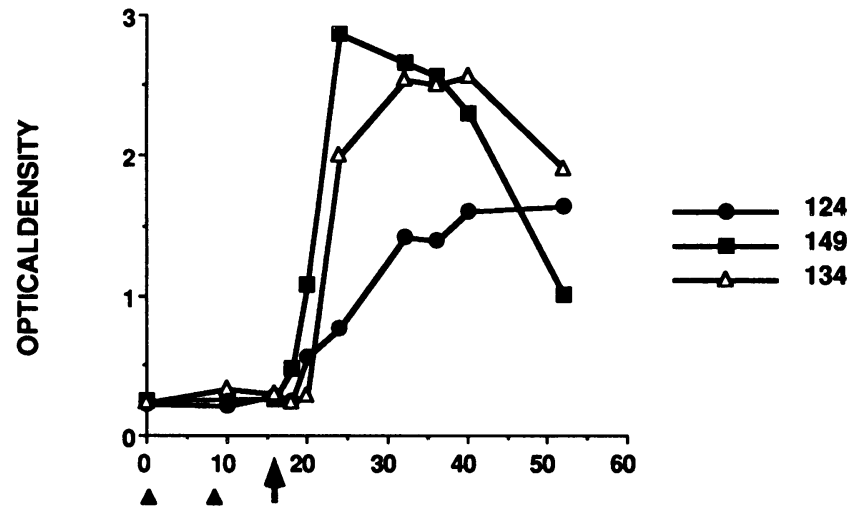

LOW DOSE INFECTION

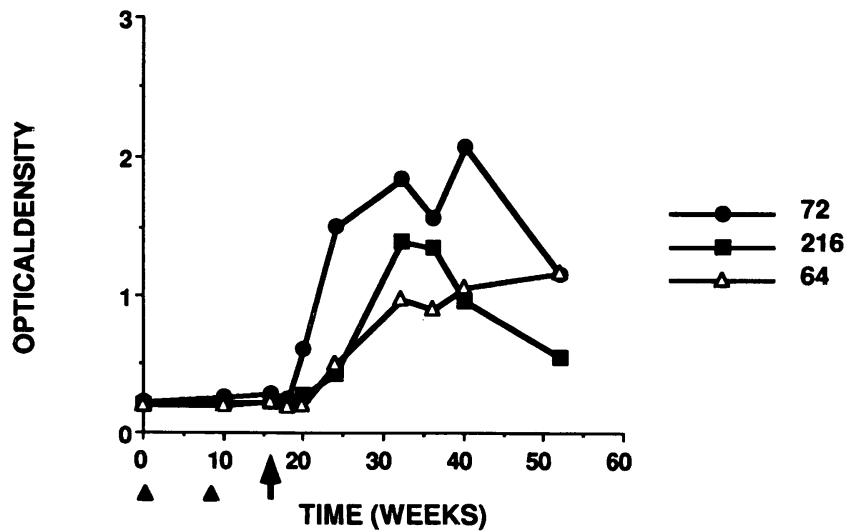

Figure 2. Antibody binding to V3 loop peptide. A synthetic peptide corresponding to AA $297-330$ of gp $120_{\text {IIIB }}$ was used as antigen in an ELISA. Sera were tested at a 1:1,000 dilution. Experimental details and labels are as for Fig. 1. Control chimpanzees (immunized with herpes symplex virus $\mathrm{gD}$ ) are indicated with open triangles. infection. Early sera ( 8 wk postinfection) bound to multiple peptides over the central portion of the loop, while antibodies obtained later ( 9 mo postinfection) were more focused on peptides located at the very tip of the loop. This latter pattern is identical to that of laboratory workers infected with HIV $_{\text {IIIB }}$ and is distinctly different from that seen in humans who have been immunized with gp 160 subunit vaccines $(15)$.

Neutralization by chimpanzee sera. Neutralization of HIV expressing the homologous envelope was studied with a FIA using the $\mathrm{CD}^{+}{ }^{+} \mathrm{HeLa}$ cell line $1022(20,22)$ (Fig. 4). Neutralization was measured as inhibition in the numbers of foci. Vaccination did not result in production of any detectible neutralizing antibody. After challenge, the high dose group produced neutralizing antibody more rapidly than the animals challenged with a low infectious dose. In the low dose group, the control animal produced less neutralizing antibody at each time point than either of the gp160-vaccinated animals, suggesting that vaccination may have enhanced the production of neutralizing antibody. However, this was not the case in the high dose animals. The production of neutralizing antibody was not closely correlated with either anti-gp160, anti-V3, or CD4-gp120 blocking antibody levels. Although Fig. 4 only shows data from a single antibody dilution, sera from each of the time points have been titered over a range of dilutions from $1: 20$ to $1: 540$ with the same results.

A component of neutralizing antibody is antibody that blocks the interaction between CD4 and gp120 (23). We have measured this interaction using a previously described solid phase assay (15). Immunization did not result in the production of such antibodies. After infection, five of six chimpanzees developed blocking antibodies. There was no relationship between immunization or infectious dose and the development of blocking antibodies after exposure to HIV (data not shown).

Epitope mapping the anti-envelope response. We mapped the fine specificity of the anti-envelope response using synthetic peptides. We have identified immunogenic regions of gp160 with a set of 283 overlapping 12-mer peptides on immobilized supports using the method of Geysen et al. (19). This method is semiquantitative at best, since only a single serum can be tested in each experiment. To quantitate antibody levels to important epitopes, we have used soluble peptides adsorbed to the wells of microtiter plates. Fig. 5 shows the results of Geysen mapping on a single chimpanzee at three different time points. No significant binding was observed before vaccination. By 8 wk after infection an immune response to well-defined areas of gp 160 had developed. Immunodominant regions included the V3 loop (AA 300-330), carboxy terminus of gp120 (AA 480-510), previously defined immunodominant regions in the amino-terminal third of gp41 (AA 580-610), mid gp41 (AA 700-730), and the carboxy terminus of gp41 (AA 820-850). At 9 mo postinfection, there had been some shift in the epitope specificity, but many of the same regions remained immunodominant. In comparing the different chimpanzees, antibody was detected to the same regions of gp160, and there was no difference between the control and gp 160 -vaccinated animals.

In a previous report we demonstrated that immunization of humans with gp 160 resulted in a marked antibody response to a region in mid-gp41 (AA 720-740) that was not seen in lab workers infected with $\mathrm{HIV}_{\text {IIIB }}$ (15). Antibodies to this region were originally reported to be neutralizing $(24,25)$, although this remains a matter of much controversy (15). We have used 
72

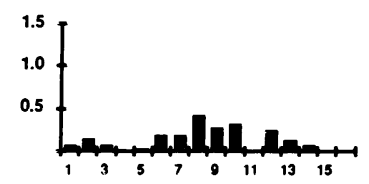

216

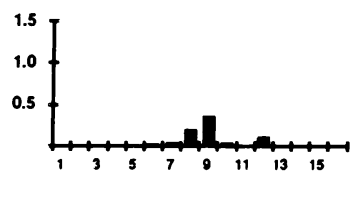

64

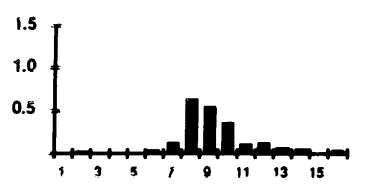

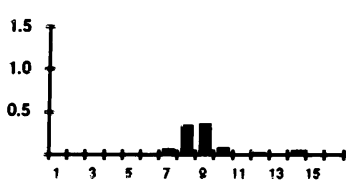

A EARLY SERA

124

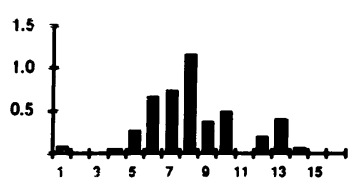

B LATE SERA
124

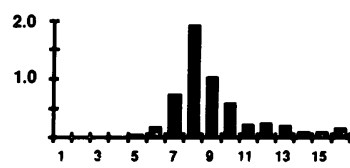

72

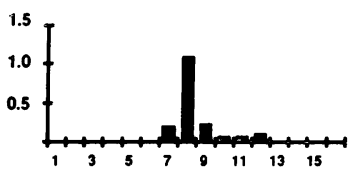

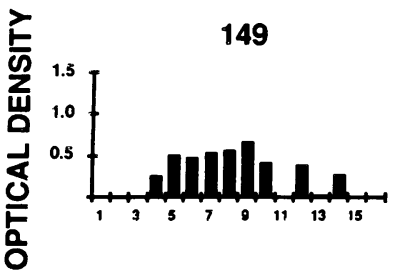

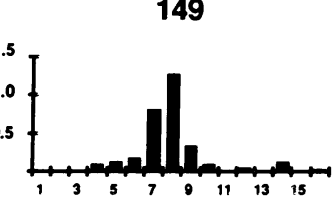

216

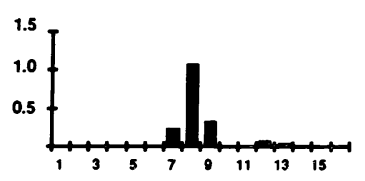

PEPTIDE NUMBER

134

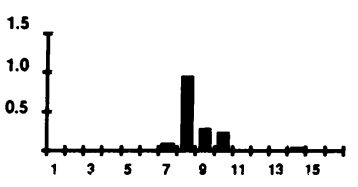

64

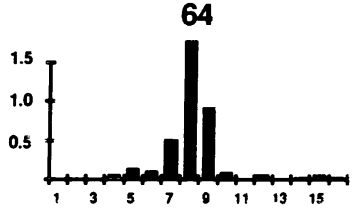

Figure 3. Fine specificity of the anti-V3 response. Sera obtained $8 \mathrm{wk}(A)$ and $(B) 9$ mo postinfection. Epitope mapping was performed using "Geysen" peptides covalently attached to the tips of plastic supports. A 1:5,000 dilution of serum was tested. Binding was detected with antihuman Ig conjugated to alkaline phosphatase and a chromogenic substrate. Optical density is shown on the vertical axis. Only a single serum was tested at a given time, so quantitative comparisons cannot be made. The peptides attached to the supports are arrayed on the horizontal axis with the closest to the amino terminus on the left (no. 1) and proceeding toward the carboxy-terminal peptides to the right. The peptides were: (1) VQLNQSVEINCT, (2) NQSVEINCTRPN, (3) VEINCTRPNNNT, (4) NCTRPNNNTRKS, (5) RPNNNTRKSIRI, (6) NNTRKSIRIQRG, (7) RKSIRIQRGPGR, (8) IRIQRGPGRAFV, (9) QRGPGRAFVTIG, (10) PGRAFVTIGKIG, (11) AFVTIGKIGNMR, (12) TIGKIGNMRQAH, (13) KIGNMRQAHCNI, (14) NMRQAHCNISRA, (15) QAHCNISRAKWN, (16) CNISRAKWNNTL.

an ELISA to measure antibody to a peptide representing this region (Fig. 6). The results clearly indicate that vaccination with gp160 primed animals for the induction of this antibody subsequent to infection. Low levels of antibody to the midgp41 epitope were seen after immunization and before infectious challenge. After infection, high levels of antibody to mid-gp41 were detected in the gp160-vaccinated but not the control animals. Thus, vaccination with gp160 can shape the epitope specificity of the subsequent immune response to HIV infection.

We have identified the V1 loop of gp120 (AA 131-156) as an immunodominant epitope in lab workers infected with HIV $_{\text {IIIB }}$ (S. H. Pincus, et al., manuscript submitted for publication). Previous studies by others failed to identify this epitope because of the variability of the region and the inability to test for antibodies on a peptide representing the sequence of the infecting virus. We have tested the chimpanzee sera for the presence of antibody to the V1 loop (data not shown). Such antibody was seen in three of the six chimpanzees tested, all of whom were vaccinated with gp 160 . Antibody did not arise un- til at least 4 mo postinfection. It is possible that with more time the other chimpanzees will also develop anti-V1 antibody.

\section{Discussion}

Processing and presentation of antigen to the immune system have been the subject of detailed molecular analyses and involve many steps. Differences in antigen presentation can affect the outcome of the immune response. The immune response to the HIV envelope protein(s) gp120 and gp160 is particularly well studied because of its importance in developing a vaccine to prevent AIDS. We fine mapped the human (15), and now chimpanzee, anti-Env response. Because our studies were restricted to subjects exposed to a single strain of HIV (IIIB), their response can be studied in greater detail than has previously been done. The results clearly implicate gp160 vaccinia in stimulating production of antibody to a particular epitope. These analyses emphasize that the form in which an antigen (gpl60) is presented as immunogen (vaccinia, as op- 

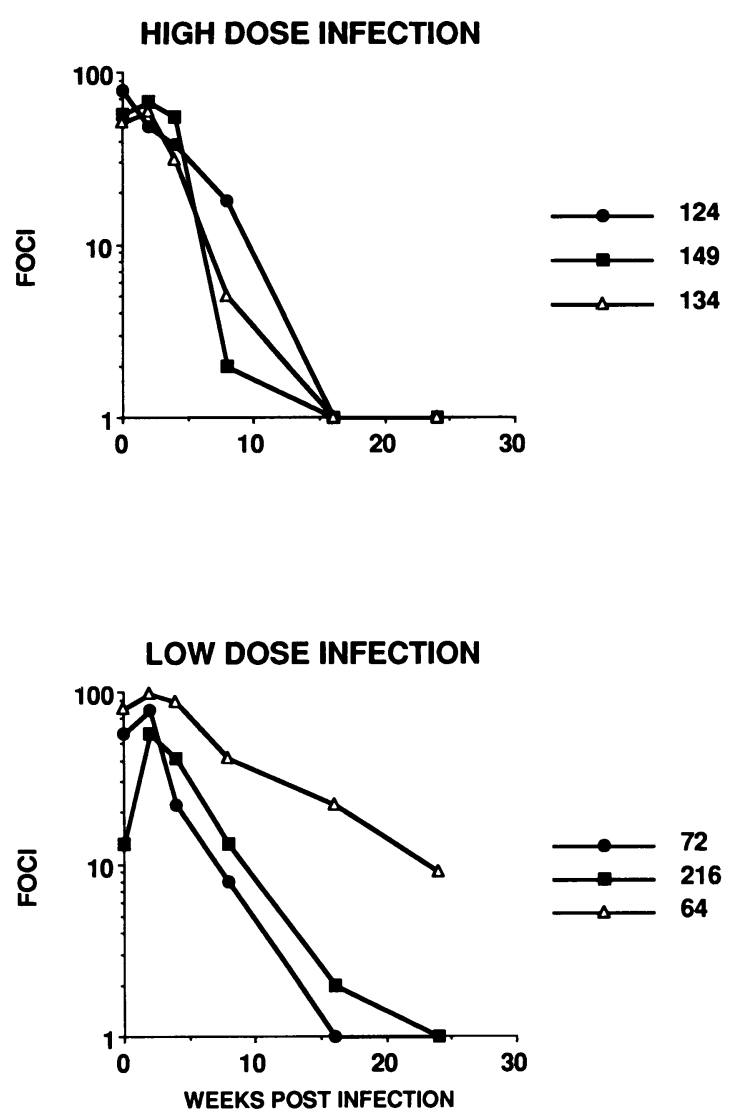

Figure 4. Neutralizing antibody. Neutralization of the molecularly cloned NL4-3 isolate was measured by focal immunoassay. Sera (1:20) were mixed with a viral stock, then incubated on a monolayer of $1022\left(\mathrm{CD}^{+}{ }^{+} \mathrm{HeLa}\right)$ cells. HIV foci were detected $3 \mathrm{~d}$ later via immunoperoxidase staining. The number of foci was plotted as a function of weeks postinfection. Antibody-mediated neutralization was measured as inhibition of focus formation. Control animals are indicated with open triangles. Control wells containing nonimmune sera contained $97.4 \pm 9.4$ foci (mean and SEM of 12 wells).

posed to HIV or recombinant protein) influences the epitope specificity of the resulting response, not just the magnitude and kinetics. The form of the antigen can influence presentation in multiple ways, including persistence of antigen, changing the kinetics of antigen uptake into antigen-presenting cells, and even altering which populations of cells may serve to present antigen. These studies underscore that factors other than the primary structure of the antigen itself and genetic makeup of the responding animal can define epitope specificity.

Human trials of AIDS vaccines are ongoing and efficacy testing will soon begin. Initial trials have involved subunit vaccines based on the HIV envelope proteins gp160 and gp120, or fragments thereof. The material is of low inherent immunogenicity. Multiple injections of 50-640 $\mu \mathrm{g}$ of recombinant protein are required to produce sustained antibody responses (13); in comparison, immunization of humans with hepatitis B surface antigen requires three injections of $10 \mu \mathrm{g}$. Developing countries will have difficulty paying for such quantities of vaccines. Fortunately, protocols are being developed that allow for the production of high levels of antibodies, but use less recombinant antigen. One such protocol involves priming with live gp160 vaccinia followed by a boost with recombinant gp160
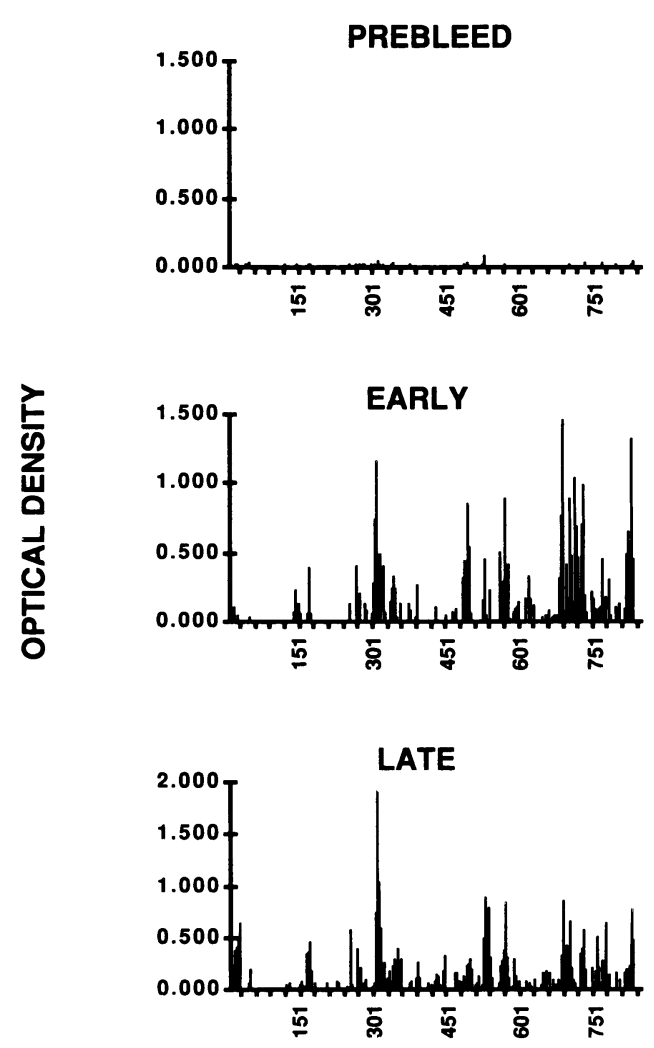

Figure 5. Epitope mapping the anti-gp160 response. Sera from chimpanzee 124 at three different time points were analyzed on a set of 283 overlapping 12-mer "Geysen" peptides (having a nine-AA overlap) as described in Fig. 4. The horizontal axis is numbered according to the AA number of the amino terminus of the peptide. Early serum is $8 \mathrm{wk}$ postinfection and late serum is 9 mo postinfection.

(9). Because of the success of this "prime/boost" protocol, vaccinia priming may be used in some phase II and III clinical trials.

In this report we have documented the antibody response of chimpanzees vaccinated with gp $160_{\text {IIIB }}$ vaccinia and then infected with the same strain of HIV. These experiments were designed to determine the effect of vaccination upon the antibody response to infection, as well as to study the evolution of this response with time after infection. We find that unsuccessful vaccination affected both the kinetics and epitope specificity of the subsequent antibody response to HIV infection, even though vaccination alone induced only minimal responses. Alterations induced by failed vaccination in chimpanzees were similar to those seen in humans immunized with gp160 vaccinia (15).

A unique effect of gp 160 vaccination is the development of antibody to the mid-gp41 epitope (Fig. 6). Low levels of this antibody appeared before infection; antibody titers rose dramatically within $4 \mathrm{wk}$ of infection. Little if any such antibody occurred in control vaccinated chimpanzees. These data resemble our findings on human vaccinees receiving IIIB-based envelope subunit vaccines and on humans infected with $\mathrm{HIV}_{\text {IIIB }}$ (15; and S. H. Pincus and K. G. Messer, unpublished results). In those studies, vaccinees in the prime/boost protocols produced high levels of antibody to the mid-gp41 epitope. None was seen in the lab worker sera. There were sporadic responders in other vaccine protocols, and only 3 of 28 random HIV sam- 


\section{HIGH DOSE INFECTION}

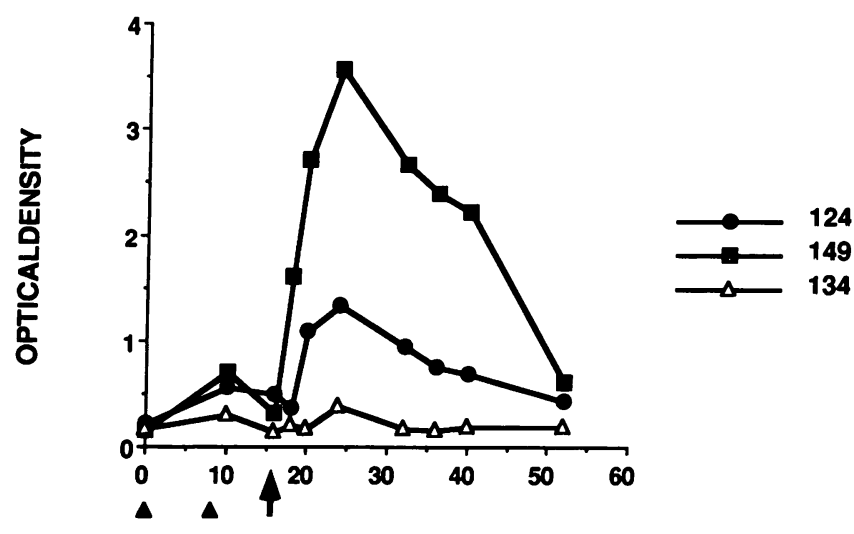

\section{LOW DOSE INFECTION}

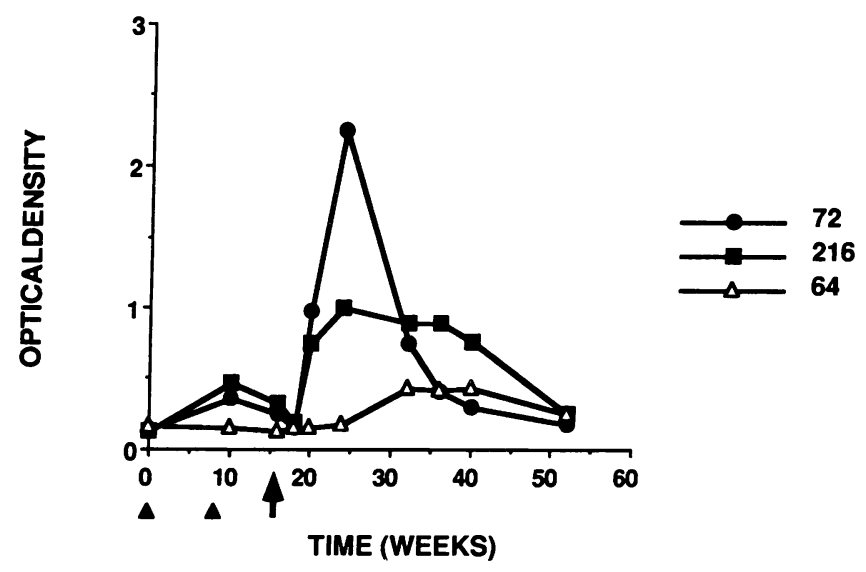

Figure 6. Binding of chimpanzee sera to mid-gp41 peptide. A 1:1,000 dilution of chimpanzee serum was tested for binding to a peptide corresponding to AAs 718-743 of gp $160_{\text {IIIB }}$ by ELISA. The optical density obtained (vertical axis) was plotted against time postvaccination. The times of priming, boosting, and infectious challenge are indicated. Control animals are indicated with open triangles.

ples were antibody positive. All told, the data strongly implicate gp 160 vaccinia as the agent responsible for priming for the induction of anti-mid-gp41 antibody.

Having demonstrated that antibody specific to the midgp41 epitope is induced by gp160-vaccinia, we should ask if such antibody has functional significance. Unfortunately, the data are contradictory. Most structural predictions suggest this epitope lies on the cytoplasmic side of the cell membrane (26). Yet there are several reports that this epitope has functional importance $(24,25,27-29)$. Our data with monoclonal antibodies and immunotoxins indicate that this epitope is not surface exposed, nor is it a target of neutralizing antibody (15). Further studies in this area, involving common reagents, should soon define these issues regarding the mid-gp4l epitope.

The nature of neutralizing antibodies is important to determine. At least two different components have been defined: anti-V3 and CD4-gp1 20 blocking antibodies $(23,30)$. In the focal immunoassay we used, antibody was only present during incubation of target cells with cell-free virus; thus, this assay only measured early neutralization events. However, in studies of human vaccinees we have found that data derived with this assay correspond well to those obtained from more conventional assays in which antibody is present for the entire period of the assay (15). Our previous results indicated that levels of neutralizing antibody correlated best with the fine specificity of the anti-V3 response and not with total levels of anti-Env, antiV3, or CD4-gp120 blocking antibody (15). The kinetics of the chimpanzee response support this notion. Anti-Env, V3, and CD4 blocking antibodies reached peak values at $8 \mathrm{wk}$ postinfection, and then either remained the same or began to decrease, while levels of neutralizing antibody climbed throughout the observation period (Fig. 4; and unpublished data). However, during the period between 8 wk and 9 mo postinfection, the fine specificity of the anti-V3 response evolved so that it was more focused on the tip of the V3 loop, again suggesting that neutralization correlated best with the fine specificity of antibody to this region. Another factor in the increase in neutralizing antibody with time could be "affinity maturation" of the immune response, a well-described phenomenon in which the affinity of an immune response increases with time after antigen exposure (31).

Each animal model of HIV infection has its own limitations. The chimpanzee is the only nonhuman that can be infected with HIV and in which the natural immune response to this infection can be followed. The number of experimental animals available is a major restriction in this model. We have used six in these studies and obtained results from two additional control chimpanzees, who were infected with different doses and forms of $\mathrm{HIV}_{\text {IIIB }}$ than these chimpanzees. Results from those animals are consistent with those described here (S. H. Pincus and K. G. Messer, unpublished results). Another limitation of chimpanzee studies is the absence of clinical disease, precluding correlation of the immune response and disease progression.

Successful vaccine protection for chimpanzees against HIV infection has been obtained (2-4). We have now obtained sera from $>20$ chimpanzees who have been immunized according to different protocols and challenged with $\mathrm{HIV}_{\mathrm{IIIB}}$. Many were protected, but some were not. In an effort to define correlates of protection, we are studying these sera as described here. At the same time we have extended our work with human vaccinees to include those receiving recombinant $\mathrm{gp} 120_{\mathrm{IIB}}$ and $\mathrm{gp} 160_{\mathrm{IIIB}}$ produced in mammalian cell culture. By comparing three populations (lab workers, vaccinees, and chimpanzees) who were all exposed to gp 160 derived from the same strain of HIV but in different forms, we are defining the anti-Env antibody response at a molecular level and are evaluating factors influencing its epitope specificity. These studies have implications for the design and evaluation of HIV vaccines.

\section{Acknowledgments}

We thank Zhang Pei and Tracy Wrey for experimental assistance, Jorg Eichberg and his staff at the Southwest Foundation for care of the animals and sample handling, and Susan and Carole Smaus for secretarial support. John Swanson, Harlan Caldwell, and John Moore have read the manuscript and provided helpful comments.

\section{References}

1. Murphey-Corb, M., L. N. Martin, B. Davison-Fairburn, R. C. Montelaro, M. Miller, M. West, S. Ohkawa, G. B. Baskin, J.-Y. Zhang, S. D. Putney, A. C. 
Allison, and D. A. Eppstein. 1989. A formalin-inactivated whole SIV vaccine confers protection in macaques. Science (Wash. DC). 246:1293-1297.

2. Berman, P. W., T. J. Gregory, L. Riddle, G. R. Nakamura, M. A. Champe, J. P. Porter, F. M. Wurm, R. D. Hershberg, E. K. Cobb, and J. W. Eichberg. 1990 Protection of chimpanzees from infection by HIV-1 after vaccination with recombinant glycoprotein gp120 but not gp160. Nature (Lond.). 345:622-625.

3. Girard, M., M.-P. Kieny, A. Pinter, F. Barre-Sinoussi, P. Nara, H. Kolbe, K. Kusumi, A. Chaput, T. Reinhart, E. Muchmore, J. Ronco, M. Kaczorek, E. Gomard, J.-C. Gluckman, and P. N. Fultz. 1991. Immunization of chimpanzees confers protection against challenge with human immunodeficiency virus. Proc. Natl. Acad. Sci. USA. 88:542-546.

4. Fultz, P. N., P. Nara, F. Barre-Sinoussi, A. Chaput, M. L. Greenberg, E. Muchmore, M.-P. Kieny, and M. Girard. 1992. Vaccine protection of chimpanzees against challenge with HIV-1-infected peripheral blood mononuclear cells Science (Wash. DC). 256:1687-1690.

5. Hu, S.-L., K. Abrams, G. N. Barber, P. Moran, J. M. Zarling, A. J. Langlois, L. Kuller, W. R. Morton, and R. E. Benveniste. 1992. Protection of macaques against SIV infection by subunit vaccines of SIV envelope glycoprotein gp 160 . Science (Wash. DC). 255:456-459.

6. Hu, S.-L., P. N. Fultz, H. M. McClure, J. W. Eichberg, E. K. Thomas, J. Zarling, M. C. Singhal, S. G. Kosowski, R. B. Swenson, D. C. Anderson, and G. Todaro. 1987. Effect of immunization with a vaccinia-HIV env recombinant on HIV infection of chimpanzees. Nature (Lond.). 328:721-723.

7. Hu, S.-L. 1990. Biochemical and immunologic characterizations of HIV envelope glycoproteins expressed by recombinant vaccinia virus. In AIDS Vaccine Research and Clinical Trials. S. D. Putney, and D. P. Bolognesi, editors. Marcel Dekker, Inc., New York. 197-217.

8. Dolin, R., B. S. Graham, S. B. Greenberg, C. O. Tacket, R. B. Belshe, K. Midthun, M. L. Clements, G. J. Gorse, B. W. Horgan, R. L. Atmar, et al., and NIAID AIDS Vaccine Clinical Trials Network. 1991. The safety and immunogenicity of a human immunodeficiency virus type 1 (HIV-1) recombinant gp160 candidate vaccine in humans. Ann. Intern. Med. 114:119-127.

9. Graham, B. S., T. J. Matthews, R. B. Belshe, M. L. Clements, R. Dolin, P. F. Wright, G. J. Gorse, D. H. Schwartz, M. C. Keefer, D. P. Bolognesi, et al., and NIAIDS AIDS Vaccine Clinical Trials Network. 1993. Augmentation of human immunodeficiency virus type 1 neutralizing antibody by priming with gp160 recombinant vaccinia and boosting with rgp 160 in vaccinia-naive adults. J. Infect. Dis. 167:533-537.

10. Cooney, E. L., A. C. Collier, P. D. Greenberg, R. W. Coombs, J. Zarling, D. E. Arditti, M. C. Hoffman, S.-L. Hu, and L. Corey. 1991. Safety of and immunological response to a recombinant vaccinia virus vaccine expressing HIV envelope glycoprotein. Lancet. 337:567-572.

11. Graham, B. S., R. B. Belshe, M. L. Clements, R. Dolin, L. Corey, P. F. Wright, G. J. Gorse, K. Midthun, M. C. Keefer, N. J. Roberts, Jr., et al., and AIDS Vaccine Clinical Trials Network. 1992. Vaccination of vaccinia-naive adults with HIV-1 gp160 recombinant vaccinia (HIVAC-le) in a blinded, controlled, randomized clinical trial. J. Infect. Dis. 166:244-252.

12. Wintsch, J., C.-L. Chaignat, D. G. Braun, M. Jeannet, H. Stalder, S. Abrignani, D. Montagna, F. Clavijo, P. Moret, J.-M. Dayer, et al. 1991. Safety and immunogenicity of a genetically engineered human immunodeficiency virus vaccine. J. Infect. Dis 163:219-225.

13. Fast, P. E., and M. C. Walker. 1993. Human trials of experimental AIDS vaccines. AIDS (Phila.). 7:S147-159.

14. Cohen, J. 1991. AIDS vaccine meeting: international trials soon. Science (Wash. DC). 254:647.

15. Pincus, S. H., K. G. Messer, D. H. Schwartz, G. K. Lewis, B. S. Graham,
W. A. Blattner, and G. Fisher. 1993. Differences in the antibody response to human immunodeficiency virus-1 envelope glycoprotein ( $g p 160$ ) in infected laboratory workers and vaccinees. J. Clin. Invest. 91:1987-1996.

16. Hu, S.-L., S. G. Kosowski, and J. M. Dalrymple. 1986. Expression of AIDS virus envelope gene in recombinant vaccinia viruses. Nature (Lond.). 320:537-540.

17. Adachi, A., H. E. Gendelman, S. Koenig, T. Folks, R. Willey, A. Rabson, and M. A. Martin. 1986. Production of acquired immunodeficiency syndromeassociated retrovirus in human and nonhuman cells transfected with an infectious molecular clone. J. Virol. 59:284-291.

18. Myers, G., B. Korber, J. A. Berzofsky, R. F. Smith, G. N. Pavlakis, A. Gifford, J. Lawrence, R. Lenroot, and K. MacInnes. 1992. Human Retroviruses and AIDS 1992. A Compilation and Analysis of Nucleic Acid and Amino Acid Sequences. Los Alamos National Laboratory, Los Alamos, NM.

19. Geysen, H. M., S. J. Rodda, T. J. Mason, G. Tribbick, and P. G. Schoofs. 1987. Strategies for epitope analysis using peptide synthesis. J. Immunol. Methods. 102:259-274.

20. Pincus, S. H., K. Wehrly, and B. Chesebro. 1991. Use of a focal infectivity assay for testing susceptibility of HIV to antiviral agents. BioTechniques. 10:336342.

21. Chesebro, B., and K. Wehrly. 1988. Development of a sensitive quantitative focal assay for human immunodeficiency virus infectivity. J. Virol. 62:37793788.

22. Chesebro, B., K. Wehrly, J. Metcalf, and D. E. Griffin. 1991. Use of a new CD4-positive HeLa cell clone for direct quantitation of infectious human immunodeficiency virus from blood cells of AIDS patients. J. Infect. Dis. 163:64-70.

23. Steimer, K. S., C. J. Scandella, P. V. Skiles, and N. L. Haigwood. 1991. Neutralization of divergent HIV-1 isolates by conformation-dependent human antibodies to gp 120. Science (Wash. DC). 254:105-108.

24. Kennedy, R. C., R. D. Henkel, D. Pauletti, J. S. Allan, T. H. Lee, M. Essex, and G. R. Dreesman. 1986. Antiserum to a synthetic peptide recognizes the HTLV-III envelope glycoprotein. Science (Wash. DC). 231:1556-1559.

25. Evans, D. J., J. McKeating, J. M. Meredith, K. L. Burke, K. Katrak, A. John, M. Ferguson, P. D. Minor, R. A. Weiss, and J. W. Almond. 1989. An engineered poliovirus chimaera elicits broadly reactive HIV-1 neutralizing antibodies. Nature (Lond.). 339:385-388.

26. Xu, J.-Y., M. K. Gorny, T. Palker, S. Karwowska, and S. Zolla-Pazner. 1991. Epitope mapping of two immunodominant domains of gp41, the transmembrane protein of human immunodeficiency virus type 1 , using ten human monoclonal antibodies. J. Virol. 65:4832-4838.

27. Chanh, T. C., G. R. Dreesman, P. Kanda, G. P. Linette, J. T. Sparrow, D. D. Ho, and R. C. Kennedy. 1986. Induction of anti-HIV neutralizing antibodies by synthetic peptides. EMBO (Eur. Mol. Biol. Organ.) J. 5:3065-3071.

28. Dalgleish, A. G., T. C. Chanh, R. C. Kennedy, P. Kanda, P. R. Clapham, and R. A. Weiss. 1988. Neutralization of diverse HIV-1 strains by monoclonal antibodies raised against a gp41 synthetic peptide. Virology. 165:209-215.

29. Broliden, P.-A., A. von Gegerfelt, P. Clapham, J. Rosen, E.-M. Fenyo, B. Wahren, and K. Broliden. 1992. Identification of human neutralization-inducing regions of the human immunodeficiency virus type 1 envelope glycoproteins. Proc. Natl. Acad. Sci. USA. 89:461-465.

30. Javaherian, K., A. J. Langlois, C. McDanal, K. L. Ross, L. I. Eckler, C. L. Jellis, A. T. Profy, J. R. Rusche, D. P. Bolognesi, S. D. Putney, and T. J. Matthews. 1989. Principal neutralizing domain of the human immunodeficiency virus type 1 envelope protein. Proc. Natl. Acad. Sci. USA. 86:6768-6772.

31. Eisen, H. N., and M. L. Gefter. 1990. Antibody formation. In Microbiology. 4th ed. B. D. Davis, R. Dulbecco, H. N. Eisen, and H. S. Ginsberg, editors. J. B. Lippincott Company, Philadelphia. 363-383. 